\title{
Revealing the scientific root of scratch formation on soda-lime-silica glass surface: Digging deeper into structural modification of glass surface
}

Barsheek Roy ( $\nabla$ barsheek.roy@uni-bayreuth.de)

University of Bayreuth

Andreas Rosin

University of Bayreuth

Thorsten Gerdes

University of Bayreuth

Stefan Schafföner

University of Bayreuth

Research Article

Keywords: Soda-lime-silica, Glass, Surface, Scratch, Nanostructures

Posted Date: September 28th, 2021

DOI: https://doi.org/10.21203/rs.3.rs-941767/v1

License: (c) (i) This work is licensed under a Creative Commons Attribution 4.0 International License.

Read Full License 


\section{Abstract}

Scratch formation on glass surfaces is a ubiquitous phenomenon induced by the virtue of plastic deformation, often accompanied by radial, lateral or median cracks with consequent chipping and brittle fracture caused during and after the event of dynamic abrasion instigated by shear stress by another harder material. This paper deals with the fundamental aspect of scratch formation on soda-lime-silica (SLS) glass surfaces. A constructive combination of surface-sensitive characterization tools including field emission scanning electron microscopy (FESEM), laser scanning microscopy (LSM), X-ray photoelectron spectroscopy (XPS), Raman spectroscopy and instrumented indentation technique (IIT), helped to investigate the structural cause of generation of visible scratches on SLS glass surfaces. The experimental evidences propose that a silicate network possessing a mechanically-weakening structural characteristic in terms of network connectivity confined to the region between $5 \mathrm{~nm}$ and $100 \mathrm{~nm}$ below the glass surface, is likely to cause a destructive surface scratch eminently visible to naked eyes.

\section{Introduction}

Scratch resistance of the surface of container glasses is one of the key issues for the glass industry [1-3]. Container glass- e.g. baby food and milk bottles, is essentially soda-lime-silica (SLS) glass manufactured by the conventional melt-quenching process. The current industrial technology to enhance the scratch resistance is based on the deposition of a thin layer of tin oxide hot-end coating. A standard technique is to apply the hot-end coating on the outer surface of container glass via Chemical Vapor Deposition (CVD) [4]. The tin oxide coating acts as an anchoring agent and a primer for the cold-end coating, which is a thin layer of polymeric emulsion such as polyethylene, waxes; among others. The flexible polymer chain primarily serves as a load dissipating (lubricating) agent during a scratching event to lower the coefficient of friction- consequently enhancing the scratch resistance of the glass surface $[2,3,5,6]$. This two-stage coating process is widely accepted by container glass producing companies. Other coating systems including $\mathrm{SiO}_{2}-\mathrm{TiO}_{2}$ and chromium thin films were reported to favorably modify the SLS glass surface to enhance the abrasion resistance with low wear rates $[7,8]$.

However, the technical knowledge pertaining to the parental scientific background behind the formation of scratches on glass surfaces in terms of structural properties is still limited, with a confined knowledge on the subject of distribution of surface flaws on silicate glasses with relevance to brittle fracture and consequent degradation of mechanical strength [9-11]. Tempered glasses are known to be more sensitive to visibility of scratches compared to the annealed counterpart [12]. The crack width of a typical scratch depends on the geometry of the indenter used, in addition to the applied normal load. The formation of radial, median and lateral crack systems induced by scratching with an indenter has been schematically explained. The effect of indenter geometry [13] and applied normal load on the sequential regimes of plastic deformation (micro-ductile), micro-cracking (radial cracks, median/lateral cracks), chipping and micro-abrasion phases (with increasing normal load) induced during and after unloading of indenter pertaining to scratch tests on SLS glass surface have gained significant attention in several publications [14-17]. Wondraczek and co-workers studied the dependence of scratch hardness on the composition of 
SLS glass and found increasing and decreasing trends of scratch hardness in the low load elastic-plastic deformation regime of $50-70 \mathrm{mN}$ (absence of microscopic cracks), with increasing content of $\mathrm{CaO}$ and $\mathrm{Na}_{2} \mathrm{O}$ respectively [18]. It is equally noteworthy to consider the environment in which the scratch/wear tests are conducted, which has a major influence on the mechanism of cracking behavior governing the formation of a scratch on SLS glass surface, which is largely driven by stress corrosion cracking in humid atmosphere due to attack of water molecules on the (Si-O-Si) bridging oxygens to dissociate into silanol groups $(\mathrm{SiOH})$ with consequent reduction of network connectivity [19-21].

As far as the surface structural integrity of industrial container glasses is concerned, the $\mathrm{SiO}_{2}$-rich skin is known to play a critical role; the thickness of which, depends on the cooling rate during melt-quenching process of formation of the products [22]. Mechanical injury to the glass-skin is a cause of concern with respect to available openings in the form of micro-channels for migration of network modifier cations like sodium, possible ion-exchange processes with atmospheric interaction and other detrimental features to dissolute and perturb the glass network.

The underlying principle behind the formation of an eminent scratch on glass surface visible to naked eyes is driven by the initiation and propagation of a crack induced by plastic deformation in association with chipping and micro abrasion instigated by the virtue of shear stress acting on the surfaceaccounting for a certain surface waviness and roughness [23, 24]. The length, width and depth of the formed crack govern its characteristic orientation with respect to a direct correlation with the role of the surface structural network to dissipate or confine a scratch, as discussed in the next section. The optical phenomena in relevance with reflection and scattering of the photons of visible electromagnetic wave $(400 \mathrm{~nm}$ to $700 \mathrm{~nm}$ ) interacting with the electrons of the object of interest (indented grooves and chipped off materials on glass surface) is resolved and perceived by the color-sensitive receptors of our eyes in the form of a scratch [25].

To the best of our knowledge, there is no information available on the surface structural behavior of the silicate network in terms of an elaborate analysis of network connectivity, which is responsible to trigger the formation of a visible scratch. In order to be able to discover different ways of enhancing scratch resistance on glass surface, it is essential to understand the underlying mechanism in terms of structural modifications governing the basic principle of scratch formation. In this paper, an attempt has been endeavored to illustrate the structurally "weakening elements" which are accountable for the formation of scratch on SLS glass surface. Experimental evidences by the virtue of X-ray photoelectron spectroscopy (XPS) and Raman spectroscopy have been analyzed in addition to complementarily qualitative optical micrographs to propose the fundamental science governing the formation of scratch on SLS glass surface.

\section{Results And Discussion}

The formation of a scratch is governed by the nature and live state of the SLS glass surface just before the event of scratching. The structural orientation of the silicate network plays a crucial role in addition to 
the distribution of network modifiers - governing the integrity of the surface required for absorption and dissipation of a dynamically applied load. If the externally applied force (sheer stress) is opposed by the glass surface instead of dissipating it to a larger area (wide scratch) in the neighboring vicinity of the position of the application of load, the appearance of a scratch is thought to be relatively more abrupt, dictated by the sheer dominance of the surface. A harder surface is thus likely to oppose the applied load more effectively (lower scratch depth) than a relatively softer counterpart, to promote the instigation of higher stress concentration within a smaller confined volumetric zone. This is proposed to lead to better visibility and prominence of a formed scratch on a harder surface, which succeeds the context of current discussion.

Figure 1(a) portrays the two-dimensional SEM, three-dimensional LSM and differential interference contrast (DIC) images of a particular scratch generated at a load of $5 \mathrm{~N}$ on the surface of an untreated soda-lime-silica glass sample. Figure 1(b) represents the SEM, LSM and DIC images of a scratch formed at the same load of $5 \mathrm{~N}$ on an SLS glass surface, heat-treated close to $\mathrm{T}_{\mathrm{g}}$ at $510^{\circ} \mathrm{C}$ for 30 minutes. It is clearly visible that the scratch on the heat-treated surface is more concentrated within a confined region with high volume of material pile-up (chipping), leading to higher prominence of its visibility in comparison to the untreated counterpart, which seems to be dissipated to a larger width with scattered debris. This may be attributed to higher hardness of the heat-treated specimen up to a depth of about 300 $\mathrm{nm}$ relative to the untreated specimen as observed by instrumented indentation as a function of depth from the glass surface, illustrated in Fig. 2(a). The corresponding load-discplacement curves shown in Fig. 2(b) illustrate the loading cycle and unloading cycle - representative of the behaviour of the glass network during penetration of the Vickers indenter. The lower depth of maximum penetration $\left(\mathrm{h}_{\max }\right)$ of $\mathrm{H} 510$ surface at the same load of $10 \mathrm{mN}$ relative to the untreated surface is accountable for its higher Martens hardness. The comparative structural network connectivity confined within the region of $5 \mathrm{~nm}$ to $100 \mathrm{~nm}$ is experimentally obtained by XPS 01s studies - discussed in the next section. It is essential to point out that we did not observe any distinguishable difference in hardness between the heat-treated and untreated specimens at loads greater than $10 \mathrm{mN}$ - corresponding to higher depths of penetration over $300 \mathrm{~nm}$ (bulk). The scientific reason in terms of structural modification for a 10\%-enhancement in surface hardness of a sub- $\mathrm{T}_{\mathrm{g}}$ heat-treated specimen, may be hypothesized as the repolymerization of NBOs of vicinal silanols in the inner skin (marked as layer ' 2 ' in Fig. 3) into "mechanically stronger" $Q^{4}$ units with four BOs, leading to a quartz-like strengthened skeletal network up to a certain shallow depth below the glass surface of the order of few nanometers, as experimentally evidenced by Banerjee et. al. by XPS studies in the top $10 \mathrm{~nm}$ [26]. This is schematically illustrated in Fig. 3 with typical comparative surface structures of untreated and heat-treated SLS glass.

Figure 1. SEM, DIC and LSM (projected) images of scratch generated at $5 \mathrm{~N}$ on (a) untreated (b) heattreated $\left(510^{\circ} \mathrm{C}, 30\right.$ minutes) SLS glass surface. 
Figure 2. (a) Comparative illustration of variation of hardness as a function of depth from the untreated and heat-treated SLS glass surfaces. The indentation size effect (ISE) due to dislocation strengthening necessary to accommodate plastic deformation, in addition to friction between the indenter and specimen surface [36, 37], may not be neglected at shallow depths below $100 \mathrm{~nm}$. The Martens hardness in the ordinate (y-axis) contains an axis-break up to $3900 \mathrm{~N} / \mathrm{mm}^{2}$. (b) Corresponding load-displacement curves illustrating the loading cycle (AB: untreated and $\left.A B^{\prime}: H 510\right)$ and unloading cycle representative of elastic recovery (BC: untreated and $B^{\prime} C^{\prime}$ : $\left.H 510\right)$. The serration observed in the unloading cycle ( $\left.B^{\prime} C^{\prime}\right)$ of $H 510$ specimen is a reflection of local relaxation processes during elastic recovery, which is predominantly more active during the unloading process than during loading [38].

Figure 3. Typical surface structural schematics of SLS glass (a) untreated (b) heat-treated at $510^{\circ} \mathrm{C}$ for 30 minutes. The surface $\mathrm{OH}$ groups pertaining to physisorbed and chemisorbed water molecules in the outer skin (layer 1) were assigned by ATR-IR signals. The inner skin (layer 2) containing vicinal silanol groups are speculated to repolymerize into $Q^{4}$ units during sub- $T_{g}$ heat-treatment [26] to harden the glass surface. The depth of the $\mathrm{SiO}_{2}$-rich glass skin (exchanged layer) is in the order of few nanometers, which depends on thermal history and atmospheric storage history, among other surface-influential factors.

\subsection{Investigation of silicate structure by X-ray photoelectron spectroscopy $(\sim 0-100 \mathrm{~nm})$}

X-ray photoelectron spectroscopy (XPS) is a very powerful surface-sensitive technique to determine the localized atomic bonding environments in addition to elemental depth profiling analysis in nanometer ranges of depth below the glass surface. At the beginning, an XPS measurement was performed on the top surface without any sputtering. The information obtained is confined within a depth of $5 \mathrm{~nm}$ corresponding to this measurement. Figure 4 portrays the XPS results of the surfaces of untreated and heat-treated specimens (before scratch test) in terms of 01s peak deconvolution, centered around their corresponding binding energies (assignment of spectral peak fits: [26, 27]). The 01s peak fittings were performed freely without any constraints in accordance with Nesbitt et. al. [27], to report the least squares best fits. The corresponding binding energies, FWHM and normalized integrated peak areas of the deconvoluted peaks are tabulated in Table 1. The comparative differences in concentrations of nonbridging and bridging oxygens substantiate a critical evidence of the orientation of the silicate structure (network connectivity) in addition to the distribution of network modifiers, which may govern the mechanistic driving force of the formation of a scratch on SLS glass surface. Figure 4(a) shows a comparative deconvoluted $01 \mathrm{~s}$ illustration with respect to a clear distinction between untreated and heattreated surfaces in terms of a noteworthy difference in concentration of BOs and NBOs corresponding to their respective binding energies, ensuing the subsequent illustration. The normalized integrated peak areas were used for quantitative computation of the concentration of bridging and non-bridging oxygens present on surfaces of both the specimens. The evaluated concentrations were comparatively plotted in Fig. 4(b). The presence of a relatively high concentration of bridging oxygens on the surface (within a depth of $5 \mathrm{~nm}$ ) of the heat-treated specimen is clearly noticeable, which complements our hypothesis of a strengthened silicate network due to the presence of repolymerized $\mathrm{Q}^{4}$ units on a sub-T $\mathrm{g}$ heat-treated 
surface, giving rise to higher (nano) hardness, as observed by instrumented indentation at a load of 10 $\mathrm{mN}$. Moreover, the presence of relatively lower concentration of "mechanically weakening elements", namely NBOs and $\mathrm{SiOH} / \mathrm{H}_{2} \mathrm{O}$ species on an SLS surface heat-treated near $\mathrm{T}_{\mathrm{g}}$ further justifies the network strengthening effect induced by the virtue of thermal treatment. Thus, a combination of high concentration of bridging oxygens and low population of mechanically weakening elements up to a depth of about $5 \mathrm{~nm}$ indicated a strong and rigid network possessed by the heat-treated surface; in other words, the surface porosity [28] was reduced by sub- $\mathrm{T}_{\mathrm{g}}$ heat treatment.

The structural network connectivity was subsequently investigated as a function of depth from the glass surface (up to about $100 \mathrm{~nm}$ ) by $\mathrm{Ar}^{+}$sputtering. The heat-treated specimen seemed to attain a saturation between 3 and 3.5 in terms of the computed atomic ratio of total oxygen to silicon, $\mathrm{O}_{\text {Total }} / \mathrm{Si}$ (dominated by the presence of $Q^{1}$ and $Q^{2}$ species), while the untreated counterpart saturated at a ratio close to 3 , indicating a major dominance by a potentially high population of $\mathrm{Q}^{2}$ species - illustrated in Fig. 5 . It is to be noted that the data point corresponding to " 0 minutes" indicates a surface measurement without sputtering, the depth of information of which is confined within a depth of $5 \mathrm{~nm}$ below the surface. The $\mathrm{H} 510$ surface seemed to contain an abundance of free oxygen $\left(\mathrm{O}^{2-}\right)$ indicated by a very high $\mathrm{O}_{\text {Total }} / \mathrm{Si}$ ratio of 4.7. These free oxygens are thought to occupy the voids within the repolymerized $Q^{4}$ units present on the heat-treated surface as hypothetically schematized in Fig. 3(b), in accordance with the XPS experimental results of a sub- $\mathrm{T}_{\mathrm{g}}$ heat-treated surface by Banerjee et. al. [26]. We complement their findings by observing high concentration of free oxygens on the surface by our experimental investigations. Moreover, Nesbitt et. al. also reported the presence of free oxygens in the form of $\mathrm{O}^{2-}$ on the glass surface by complementary XPS and NMR studies [27]. The charge neutrality is thought to be taken care of by the modifier cations. The second probable reason to account for an $\mathrm{O} / \mathrm{Si}$ ratio greater than $4-$ could be the presence of physisorbed or chemisorbed water adsorbed from the atmosphere before subjecting the heattreated specimen to XPS analysis. It is noteworthy that the binding energy of the Na1s spectral line is close to $1075 \mathrm{eV}$, in contrast to a low binding energy of around $530 \mathrm{eV}$ for $01 \mathrm{~s} \mathrm{spectral} \mathrm{line,} \mathrm{which}$ theoretically implies that the photoelectrons of $\mathrm{Na} 1 \mathrm{~s}$ and $01 \mathrm{~s}$ are ejected from slightly different depths (of the order of probably a couple of nanometers, which may still not be neglected) corresponding to any data point of sputtering. Hence, we preferred to avoid a comparative analysis of Na1s and 01s orbitals.

Nevertheless, the aforementioned findings clearly demonstrate that the surface of the $\mathrm{H} 510$ specimen up to about $5 \mathrm{~nm}$ was mechanically stronger than the untreated surface, while the reverse holds true for the depth range of around $5 \mathrm{~nm}$ to $100 \mathrm{~nm}$ (mechanically weaker). It is necessary to point out that although the atomic ratio of $\mathrm{O}_{\text {Total }} / \mathrm{Si}$ corresponding to the data point of ' 0 minutes' (surface measurement without sputtering) for the $\mathrm{H} 510$ surface is considerably high, it does not indicate a structurally weakened network due to compensation by high population of BOs as described earlier.

Assuming an estimated etching rate of around $1 \mathrm{~nm} / \mathrm{min}$ with $\mathrm{Ar}^{+}$sputtering - considering the report of Yamanaka et. al. (50 nm/hr.) with respect to XPS studies on float glass surface [29], it can be assumed that the information was obtained up to a depth of around $100 \mathrm{~nm}$ with 110 minutes of $\mathrm{Ar}^{+}$sputtering at 5 $\mathrm{kV}$, concerning the SLS glass used in this study. Although argon ion sputtering was reported to cause 
potential surface damage in terms of possible migration of mobile alkali ions in addition to possible surface modification by long duration XPS experiments [30,31], it is still a widely used method for XPS depth profiling on glass surface and shouldn't affect the analysis of $01 \mathrm{~s}$ orbital presented in this work, pertaining to an experimental $\mathrm{Ar}^{+}$sputtering time of less than 2 hours at $5 \mathrm{kV}$.

Figure 4. XPS results of untreated and heat-treated SLS surfaces $(0-5 \mathrm{~nm})$ (a) $100 \%$ Gaussian deconvolution of 01s orbital (b) Comparative illustration of distribution of bridging oxygens (BOs), nonbridging oxygens (NBOs) and $\mathrm{SiOH} / \mathrm{H}_{2} \mathrm{O}$ species on both the surfaces.

Table 1

Binding energy, FWHM and \% area of deconvoluted 01s peaks of untreated and heat-treated surfaces

\begin{tabular}{|c|c|c|c|c|c|c|c|c|c|}
\hline Specimen & NBO & & & BO & & & $\mathrm{SiOH} / \mathrm{H}_{2} \mathrm{C}$ & & \\
\hline & $\begin{array}{l}\text { BE } \\
(\mathrm{eV})\end{array}$ & $\begin{array}{l}\text { FWHM } \\
(\mathrm{eV})\end{array}$ & $\begin{array}{l}\text { Area } \\
(\%)\end{array}$ & $\begin{array}{l}\mathrm{BE} \\
(\mathrm{eV})\end{array}$ & $\begin{array}{l}\text { FWHM } \\
(\mathrm{eV})\end{array}$ & $\begin{array}{l}\text { Area } \\
(\%)\end{array}$ & $\mathrm{BE}(\mathrm{eV})$ & $\begin{array}{l}\text { FWHM } \\
(\mathrm{eV})\end{array}$ & $\begin{array}{l}\text { Area } \\
(\%)\end{array}$ \\
\hline $\mathrm{H} 510$ & 529.87 & 1.17 & 17.77 & 531.41 & 2.03 & 80 & 532.07 & 1.11 & 2.23 \\
\hline Untreated & 530.09 & 1.61 & 20.35 & 531.51 & 1.35 & 62.09 & 532.35 & 1.42 & 17.56 \\
\hline
\end{tabular}

\subsection{Investigation of silicate structure by Raman spectroscopy $(\sim 1-5 \mu \mathrm{m})$}

Having studied the interesting silicate structural changes in the nanometer range of depth below the glass surface by XPS, it was essential to investigate the silicate structure in micrometer ranges of depth (before scratch test), which can be conveniently probed by confocal Raman spectroscopy with a high-resolution zscan through the depth. A depth resolution of approximately $1 \mu \mathrm{m}$ was obtained with careful optimization of different optical parameters, while bearing in mind the index of refraction. The theoretical spatial ( $x-y)$ resolution was $500 \mathrm{~nm}$ with a laser spot diameter of $1 \mu \mathrm{m}$ on the specimen surface. The high frequency (HF) broad band centred around $1090 \mathrm{~cm}^{-1}$ is commonly known to be attributed to the stretching vibrations of $Q^{3}$ species [32-34]. The noteworthy finding of this study is the distribution of Raman shift of $\mathrm{Q}^{3}$ band with respect to scattering (shift) of its position with depth from the glass surface, micrometer by micrometer. The untreated specimen showed a widely scattered distribution of $\mathrm{Q}^{3}$ shift in comparison to the heat-treated specimen, when scanned up to $5 \mu \mathrm{m}$ from the point of focus on the top surface $\mathrm{f}_{0}$ (penetration depth of 532-nm laser into silicon is reported to be $0.7 \mu \mathrm{m}$ [35]). This is illustrated in Fig. 6; the scattering limit is indicated by the respective confined boundaries. The Raman shift of $\mathrm{HF} \mathrm{Q}^{3}$ band was proposed to be a function of variation of Si-O-Si bond angle and Si-O bond length in different literatures concerned with ion-exchanged SLS glasses [33,34]. However, the scattered distribution of the shift observed in this work is thought to qualitatively indicate a more pronounced variation of Si-O-Si bond angle with depth for the untreated specimen; probably indicating a relatively more stabilised silicate network (with respect to lower variation of bond angle) for the heat-treated specimen in the bulk ( $\mu \mathrm{m}$ range), due to its limited $Q^{3}$ shift with depth. 
Depth Resolution $1 \mu \mathrm{m}$.

The Raman spectra of the HF stretching band $\left(850 \mathrm{~cm}^{-1}\right.$ to $\left.1250 \mathrm{~cm}^{-1}\right)$, taken directly on the scratched grooves of both the specimen surfaces are shown in Fig. 7. Gaussian deconvolution was performed after necessary processing of the spectra to report the best generated fit of the overlapping peaks (R-square > 0.99), which were assigned to the stretching vibrations of $\mathrm{Q}^{1}, \mathrm{Q}^{2}, \mathrm{Si}-\mathrm{O}, \mathrm{Q}^{3}$ and $\mathrm{Q}^{4}$ species- corresponding to around $950 \mathrm{~cm}^{-1}, 990 \mathrm{~cm}^{-1}, 1040 \mathrm{~cm}^{-1}, 1090 \mathrm{~cm}^{-1}$ and $1150 \mathrm{~cm}^{-1}$ respectively [33]. The surface scratch network on the untreated specimen seemed to contain more $\mathrm{Q}^{1}$ units (mechanically weakening entity), defined by larger area under the shoulder peak around $950 \mathrm{~cm}^{-1}(16.7 \%)$, relative to the H510 counterpart (only 1\%), the full width at half maxima (FWHM) being almost four times. This corroborates the preceding observation of lower variation of bond angle with depth from the heat-treated surface before scratch (stabilised initial network). The third shoulder corresponding to around $1040 \mathrm{~cm}^{-1}$ was assigned to the stretching vibration of a depolymerised Si-O unit, which was slightly debatable to be assigned to any specific $Q^{n}$ species $[32,33]$. The area under this peak was observed to be much higher for the scratched surface of the heat-treated specimen. The comparative illustration of the normalised integrated areas under the individual peaks (expressed in \%) and the corresponding FWHM values is tabulated in Table 2. However, the drawback associated with Raman spectroscopy is its inability for an accurate quantitative analysis, although the area under the peaks can be compared within a particular spectrum to draw apparent interpretive conclusions.

Considering both XPS and Raman investigations of the silicate structure, we propose the following gradient of strength (with respect to silicate network connectivity - distribution of BOs, NBOs, possible variation of Si-O-Si bond angles and $\mathrm{Q}^{\mathrm{n}}$ species with depth) of silicate network for untreated and sub-T $\mathrm{g}$ heat-treated specimens with depth from the surface-

- Untreated: weak (up to $5 \mathrm{~nm}$ ) - strong (5 to $100 \mathrm{~nm}$ ) - weak (1 to $5 \mu \mathrm{m}$ );

- Sub-T g heat-treated: strong (up to $5 \mathrm{~nm}$ ) - weak (5 to $100 \mathrm{~nm}$ ) - strong (1 to $5 \mu \mathrm{m}$ ).

Figure 7. Gaussian deconvolution of HF Raman band $\left(850 \mathrm{~cm}^{-1}\right.$ to $\left.1250 \mathrm{~cm}^{-1}\right)$ indicating the overlapping peaks corresponding to $\mathrm{Q}^{\mathrm{n}}$ species present in the scratched network of (a) untreated and (b) heat-treated surfaces. (R-square $>0.99$ in both spectral fits). 
Table 2

\% Area and FWHM of overlapping peaks present in deconvoluted HF Raman band of respective surface scratch grooves.

\begin{tabular}{|lllll|}
\hline Peak Label & \multicolumn{3}{l|}{ Normalized Integrated Area (\%) } & \multicolumn{2}{l|}{ FWHM (cm $\left.{ }^{-1}\right)$} \\
\hline & Untreated & Heat-Treated & Untreated & Heat-Treated \\
\hline $\mathrm{Q}^{1}$ & 16.7 & 1 & 82 & 24 \\
\hline $\mathrm{Q}^{2}$ & 10.4 & 13 & 56 & 182 \\
\hline v Si-0 & 2.6 & 52.5 & 31 & 200 \\
\hline $\mathrm{Q}^{3}$ & 56.2 & 31 & 83 & 84 \\
\hline $\mathrm{Q}^{4}$ & 14.1 & 2.5 & 90 & 44 \\
\hline
\end{tabular}

It is to be noted that the LSM and SEM microstructures of the scratches shown in this paper are only meant for qualitative interpretation, as we did not perform any quantitative statistical analysis in terms of variation of scratch depth and width with applied load, associated with corresponding transitions into different regimes from micro-ductility to micro-abrasion, which are well-established in literature, as discussed in the introduction. We, on the other hand, attempted to interpret the surface structural network of SLS glass to study the possible role played by silicate network connectivity to probe the structural chemistry upholding the root cause of generation of scratches. At this stage, we indeed think it to be a very interesting subject, which deserves more attention in future to extend this work in terms of ${ }^{29} \mathrm{Si}$ MAS NMR study to complementarily determine the distribution of $\mathrm{Q}^{\mathrm{n}}$ species. Our future target is to try and correlate ${ }^{29}$ Si NMR results with XPS network connectivity findings reported in this paper; in addition to separately determining the effect of surface roughness and waviness on scratches to subsequently propose a surface structural model of SLS glass, which could possibly further explain the parent cause of scratches induced during the handling and storage of container glass bottles in reality.

\section{Conclusion}

Determination of the root cause of formation of scratch on soda-lime-silica glass surface was correlated to the network connectivity of the silicate structure. For the sake of a systematic scientific investigation, a simple linear scratch test was performed on an untreated and a sub- $\mathrm{T}_{\mathrm{g}}$ heat-treated $\left(510^{\circ} \mathrm{C}, 30\right.$ minutes) SLS glass surface by a controlled, fixed load of $5 \mathrm{~N}$. Qualitative investigation of the scratches was performed by the virtue of scanning electron microstructures and laser scanning micrographs. It was observed that the heat-treated surface was more sensitive to visible formation of scratch than the untreated counterpart. Nanoindentation was performed before scratch test to investigate the (static) surface hardness at a load of $10 \mathrm{mN}$; the results indicated a $10 \%$-enhancement in surface hardness restricted to a depth of about $300 \mathrm{~nm}$ below the surface of heat-treated specimen. 
An elaborate investigation of the silicate structure was performed before scratch testing to determine the structural cause of formation of scratches. X-ray photoelectron spectroscopic results showed higher concentration of bridging oxygens and lower concentration of non-bridging oxygens on the heat-treated surface in comparison to the untreated counterpart (up to a depth of about $5 \mathrm{~nm}$ ), which is indicative of a strengthened network. As far as silicate network connectivity is concerned, the untreated specimen showed a $\mathrm{Q}^{2}$ saturation $\left(\mathrm{O}_{\text {Total }} / \mathrm{Si} \approx 3\right)$ up to a depth of about $100 \mathrm{~nm}$, while the heat-treated counterpart saturated at a slightly higher atomic ratio around 3.3, indicating a high population of $Q^{1}$ and $Q^{2}$ units. Confocal Raman spectroscopy (before scratch test) showed a relatively lower scattering of $Q^{3}$ stretching band position as a function of depth from the heat-treated glass surface (up to about $5 \mu \mathrm{m}$ ), indicating a lower variation of Si-O-Si bond angle and/or Si-O bond length in the region between $1 \mu \mathrm{m}$ and $5 \mu \mathrm{m}$ below the glass surface. Raman spectra taken over the scratched surfaces showed a relatively higher population of $Q^{1}$ species associated with the scratched network on untreated specimen corresponding to the area under the shoulder peak around $950 \mathrm{~cm}^{-1}$, indicating stronger silicate network of the scratched heattreated surface, complimentarily attributed to higher surface hardness.

Overall- a silicate network possessing the following gradient of strength is proposed to be more vulnerable to visible surface scratches in terms of distribution of $\mathrm{Q}^{\mathrm{n}}$ species, $\mathrm{SiOH} / \mathrm{H}_{2} \mathrm{O}$ species, among other accountable factors: strong ( $0-5 \mathrm{~nm})$ - weak ( $5 \mathrm{~nm}$ to $100 \mathrm{~nm})$ - strong $(1 \mu \mathrm{m}$ to $5 \mu \mathrm{m})$; the intermediate stage of 5 to $100 \mathrm{~nm}$ being the most critical region.

\section{Methods}

Soda-lime-silica container glass bottles with flat surfaces supplied by 'Wiegand-Glas' was used in this study. The surfaces of the bottles were without any hot-end and/or cold-end coatings. Cylindrical samples of diameter $25 \mathrm{~mm}$ and thickness $3 \mathrm{~mm}$ were mechanically drilled out of the bottles by means of a wetcutting process, utilising a diamond shaft. It was ensured that the surface of the obtained specimens (except the edges) were not mechanically injured during the drilling process. The samples were rinsed in distilled water, dipped in static acetone bath for 15 minutes and again rinsed in distilled water before gently blow-drying the surface by nitrogen gas (producer: 'Riessner Gase'; purity: $99.999 \%$, humidity $\leq 5 \%$ ) in room temperature. Some specimens which were characterized after the aforementioned process were labelled as "untreated" specimens. A few samples were heat-treated at $510^{\circ} \mathrm{C}$ for 30 minutes in a tube furnace (Carbolite HST 12/400), followed by naturally cooling down to room temperature (labelled as "H510" / "heat-treated"). The subsequent characterizations were performed within a day to avoid the effect of surface degradation (ageing) by the attack of atmospheric moisture with long term exposure, owing to the susceptibility of the outer skin of the glass surface (top $10 \mathrm{~nm}$ ) to constant interaction with any surrounding environment.

The elemental composition of the bulk (depth over $1 \mu \mathrm{m}$ ) of untreated SLS glass consisted of: $50.7 \% \mathrm{Si}$, $22.0 \% 0,15.9 \% \mathrm{Ca}, 8.9 \% \mathrm{Na}, 1.4 \% \mathrm{Al}$ and $1.1 \% \mathrm{~K}$ (EDX at $20 \mathrm{kV}$ ). The glass transition region (viscosity $\approx$ 
$10^{11} \mathrm{~Pa}$.s to $10^{12.3} \mathrm{~Pa}$.s) of the untreated SLS specimen was measured to be confined within the range of $559{ }^{\circ} \mathrm{C}$ to $575{ }^{\circ} \mathrm{C}$ by dilatometric study (Netzsch $402 \mathrm{E} / 7 / \mathrm{E}-\mathrm{Py}$ ) at a heating rate of $5^{\circ} \mathrm{C} / \mathrm{min}$.

\section{Characterization Techniques}

Field emission scanning electron microscope (Model: Zeiss Sigma 300 VP) was used with secondary electron signals at a low accelerating voltage of $3 \mathrm{kV}$ to generate surface-sensitive microstructures.

Laser scanning microscope (Model: Keyence VK-X1100) equipped with a class 2 laser of wavelength 404 $\mathrm{nm}$ (output power: $1 \mathrm{~mW}$ ) was used to obtain three-dimensional projected images and differential interference contrast (DIC) images of the scratches on the glass surface by a non-contact mode of measurement.

X-ray photoelectron spectroscopy (XPS) was performed by a PHI Versa Probe III spectrometer with an Al K alpha source $(1486.6 \mathrm{eV})$. The target current on the specimen holder was $3 \mu \mathrm{A}$, while the focus beam current at the Faraday cup was $302 \mathrm{nA}$. Surface charge neutralization was performed by the virtue of a dual beam charge neutralization system that utilizes both a cold cathode detector hood source and a very low energy ion source $(<10 \mathrm{eV})$ to provide turnkey charge neutralization. The pass energy was $26 \mathrm{eV}$ and the spectral resolution was about $0.2 \mathrm{eV}$. The samples (before scratch tests) were introduced to an ultra high vacuum (UHV) XPS chamber at a pressure of the order of $10^{-9} \mathrm{mbar}$, in order to investigate the structural network connectivity of both the untreated and heat-treated specimens up to a depth of about $100 \mathrm{~nm}$, for the sake of scientific interpretation of the root cause of scratch formation in terms of the difference in surface structural orientation in both the samples.

At the beginning, surface measurement was performed on each of the untreated and heat-treated SLS specimens to determine the concentration of bridging oxygens (BOs), non-bridging oxygens (NBOs) and $\mathrm{SiOH} / \mathrm{H}_{2} \mathrm{O}$ species by (100\% Gaussian) deconvolution of 01s peak. The depth from which the photoelectrons are ejected for this measurement is confined within a region of 1-3 nm below the glass surface. The surface XPS measurement was subsequently followed by sequential XPS measurements at specific time intervals accompanied by $\mathrm{Ar}^{+}$sputtering at $5 \mathrm{kV}$ to determine the $\mathrm{O}_{\text {total }} / \mathrm{Si}$ atomic ratio $\left(\mathrm{Q}^{\mathrm{n}}\right.$ network connectivity in relevance with obtained coordination number; where, ' $n$ ' indicates the number of BOs linked to a silica tertrahedron) as a function of depth from the glass surface for both the untreated and heat-treated specimens. Elemental composition profiles and corresponding binding energy curves were processed and extracted with the MultiPak software after Shirley background correction for subsequent Gaussian spectral fits.

Raman spectroscopy was carried out by Bruker Senterra II, using a laser source of $532 \mathrm{~nm}$. A 50x objective with numerical aperture of 0.65 was used to obtain a laser beam spot diameter close to $1 \mu \mathrm{m}$ on the specimen surface. The groove density of the diffraction grating was 1200 lines $/ \mathrm{mm}$. The laser power was set to $12.5 \mathrm{~mW}$ with an aperture of $25 \mu \mathrm{m}$ and an integration time of 150 seconds to obtain an optimum signal to noise ratio with a spectral resolution of $1.5 \mathrm{~cm}^{-1}$. Z-scan was performed as a function of depth 
from the glass surface with an approximate depth resolution of $1 \mu \mathrm{m}$, by stepwise moving the stage away from the focus point on the specimen surface $\left(f_{0}\right)$, while bearing in mind the index of refraction.

Instrumented indentation was performed on SLS glass surface by Fischerscope HM2000, at a load of 10 $\mathrm{mN}$ with a load application time of 20 seconds. The loading rate was fixed to "d(Sqrt)F/dt = constant". 16 indentations were performed across an array of $4 \times 4$ on each specimen. The corresponding hardness vs depth curves were dynamically recorded by "WIN-HCU" application software, by the virtue of continuous generation of load-displacement curves, throughout the depth of penetration. Martens hardness (HM) was expressed in $\mathrm{N} / \mathrm{mm}^{2}\left(\mathrm{HM}=\mathrm{F} / \mathrm{k}^{*} \mathrm{~h}_{\max }\right.$; ; wherein $\mathrm{k}=26.43$ for Vickers indenter with face angle $136^{\circ}, \mathrm{F}$ the applied load and $h_{\max }$ the maximum depth of penetration).

Scratch tests on the SLS glass surface were performed by Erichsen Lineartester Model 249 using a tip 16/505 according to ISO 1518-1, with scratch stylus ' $B$ ' having a hemispherical hard-metal tip of diameter $1 \mathrm{~mm}$. A fixed (high) load of $5 \mathrm{~N}$ was applied during the dynamic scratch tests through the length (diameter) of the glass sample at a high speed of $25 \mathrm{~mm} / \mathrm{s}$ to form straight, fine surface scratches in micro-abrasion regime, visible to naked eye. The device enabled constant load application in a uniformly controlled manner during the scratch tests. The experiments were performed in a laboratory having a surrounding temperature of about $25{ }^{\circ} \mathrm{C}$ with relative humidity in the range of about $60 \%$ to $65 \%$.

\section{Declarations}

\section{Acknowledgement}

We gratefully acknowledge the financial support for VaporCoat project within the ForCycle II programme of 'Bavarian State Ministry of the Environment and Consumer Protection' (grant number: BAF0150Fo74094). The cooperation of industrial partner- 'Wiegand-Glas', is acknowledged in addition to valuable discussions with Mr. Thomas Küpper for supplying the desired (uncoated) container glass samples.

The access to the XPS/UPS facility (PHI 5000 VersaProbe III system) at the Device Engineering Keylab in Bavarian Polymer Institute, University of Bayreuth is gratefully acknowledged along with fruitful cooperation of doctoral student- Felix Baier, Chair of Experimental Physics XI, University of Bayreuth. We would also like to thank Mr. Christian Schwarzmüller for his extensive support with the LSM imaging experiments.

\section{References}

1. Budd, S. M. Abrasion-resistant coatings for use on returnable glass containers., 77, 13-20 (1981). 
2. Southwick, R. D., Wasylyk, J. S., Smay, G. L., Kepple, J. B. \& Smith, E. C. Augustsson B.O. The mechanical properties of films for the protection of glass surfaces., 77, 41-50 (1981).

3. Awaj, Y. M., Singh, A. \& Amedie, W. Quality improvement using statistical process control tools in glass bottles manufacturing company. International Journal for Quality Research, 7, 107-126 (2013).

4. Chae, Y., Houf, W. G., McDaniel, A. H. \& Allendorf, M. D. Models for the chemical vapor deposition of tin oxide from monobutyltintrichloride. J. Electrochem. Soc, 153, C309 (2006).

5. Geotti-Bianchini, F., Preo, M. \& Pantano, C. G. Study of lubricating coatings for glass containers with optical microscopy and FTIR microscopy. Glass Technol.: Eur. J. Glass Sci. Technol., Part A, 43, 147156 (2010).

6. Beauvais, M. et. al. Film formation mechanism in glass lubrication by polymer latex dispersions., 518, 1689-1697 (2010).

7. Ramirez-Garcia, R. E. et. al. Engineered TiO2 and SiO2-TiO2 films on silica coated glass for increased thin film durability under abrasive conditions. Int. J. Appl. Ceram. Technol, 14, 39-49 (2016).

8. Lazauskas, A. et. al. Tribological properties of the two-step thermally deposited chromium films. Appl. Surf. Sci, 283, 1089-1095 (2013).

9. Varner, J. R. \& Oel, H. J. Surface defects: Their origin, characterization and effects on strength. J. NonCryst. Solids, 19, 321-333 (1975).

10. Griffith, A. A. (VI). The phenomena of rupture and flow in solids. Philos. Trans. R. Soc. London. Series A 221, 163-198(1921).

11. Yuan, F. \& Huang, L. Brittle to Ductile Transition in Densified Silica Glass. Sci. Rep, 4, 5035 (2014).

12. Schneider, J., Schula, S. \& Weinhold, W. P. Characterisation of the scratch resistance of annealed and tempered architectural glass. 8th International Conference on Coatings on Glass and Plastics ICCG8 520 4190-4198(2012).

13. Li, K., Shapiro, Y. \& Li, J. C. M. Scratch test of soda-lime glass. Acta Mater, 46, 5569-5578 (1998).

14. Matsuoka, J., Guo, D. \& Yoshida, S. Cross-section morphology of the scratch-induced cracks in sodalime-silica glass. Front. Mater, 4, 8 (2017).

15. Zakiev, I., Gogotsi, G. A. \& Storchak, M. Zakiev V. Glass Fracture during Micro-Scratching. Surfaces, 3, 211-224 (2020).

16. Sani, G., Limbach, R., Dellith, J., Sökmen, Ä. \& Wondraczek, L. Surface damage resistance and yielding of chemically strengthened silicate glasses: From normal indentation to scratch loading. J. Am. Ceram. Soc, 104, 3167-3186 (2021).

17. Moayedi, E. \& Wondraczek, L. Quantitative analysis of scratch-induced microabrasion on silica glass. J. Non-Cryst. Solids, 470, 138-144 (2017).

18. Macedo de, G. N. B. M., Sawamura, S. \& Wondraczek, L. Lateral hardness and the scratch resistance of glasses in the Na2O-CaO-SiO2 system. J. Non-Cryst. Solids, 492, 94-101 (2018).

19. Yoshida, S. et al. Fracture Mechanics of Ceramics.Springer (U.S.)101-111(2005). 
20. He, H., Qian, L., Pantano, C. G. \& Kim, S. H. Mechanochemical Wear of Soda Lime Silica Glass in Humid Environments. J. Am. Ceram. Soc, 97, 2061-2068 (2014).

21. Luo, J., Huynh, H., Pantano, C. G. \& Kim, S. H. Hydrothermal reactions of soda lime silica glass Revealing subsurface damage and alteration of mechanical properties and chemical structure of glass surfaces. J. Non-Cryst. Solids, 452, 93-101 (2016).

22. Wang, C. et. al. Study of surface changes on industrial glasses with AFM, FE-SEM, EDX, SNMS and LM Part 2. Surface changes by water drop etching, annealing at atmosphere and flame treatment. Glass Sci. Technol, 77, 273-282 (2004).

23. Feng, B. Effects of surface roughness on scratch resistance and stress-strain fields during scratch tests. AIP Advances, 7, 035217 (2017).

24. Januchta, K. \& Smedskjaer, M. M. Indentation deformation in oxide glasses: Quantification, structural changes, and relation to cracking. J. Non-Cryst. Solids, 1, 100007 (2019).

25. Barr, C. J., Wang, L., Coffey, J. K. \& Daver, F. Influence of surface texturing on scratch/mar visibility for polymeric materials: a review. J. Mater. Sci, 52, 1221-1234 (2016).

26. Banerjee, J., Bojan, V., Pantano, C. G. \& Kim, S. H. Effect of heat treatment on the surface chemical structure of glass: Oxygen speciation from in situ XPS analysis. J. Am. Ceram. Soc, 101, 644-656 (2018).

27. Nesbitt, H. W. et. al. Bridging, non-bridging and free (02-) oxygen in Na2O-SiO2 glasses: An X-ray photoelectron spectroscopic (XPS) and nuclear magnetic resonance (NMR) study. J. Non-Cryst. Solids, 357, 170-180 (2011).

28. Sewell, P. A. Porous layers at glass surfaces. Nature, 217, 441-442 (1968).

29. Yamanaka, H., Yamashita, M., Matsuoka, J., Wakabayashi, H. \& Terai, R. Depth profiling by XPS for corroded glass. J. Non-Cryst. Solids, 116, 286-288 (1990).

30. Yamamoto, Y. \& Yamamoto, K. Ar ion damage on the surface of soda-lime-silica glass. IOP Conf. Ser.: Mater. Sci. Eng, 18, 022005 (2011).

31. Sharma, A., Jain, H. \& Miller, A. C. Surface modification of a silicate glass during XPS experiments. Surf. Interface Anal, 31, 369-374 (2001).

32. Robinet, L., Coupry, C., Eremin, K. \& Hall, C. Raman investigation of the structural changes during alteration of historic glasses by organic pollutants. J. Raman Spectrosc, 37, 1278-1286 (2006).

33. Calahoo, C., Zwanziger, J. W. \& Butler, I. S. Mechanical-structural investigation of ion-exchanged lithium silicate glass using micro-Raman spectroscopy. J. Phys. Chem. C, 120, 7213-7232 (2016).

34. Terakado, N., Uchida, S., Takahashi, Y., Fujiwara, T. \& Arakawa, M. Depth analysis of a compression layer in chemically strengthened glass using depth-resolved micro-Raman spectroscopy. J. Ceram. Soc. Jpn, 124, 1164-1166 (2016).

35. Adar, F., Lee, E., Mamedov, S. \& Whitley, A. Experimental evaluation of the depth resolution of a Raman microscope. Microsc. Microanal, 16, 360-361 (2010). 
36. Pharr, G. M., Herbert, E. G. \& Gao, Y. The indentation size effect: A critical examination of experimental observations and mechanistic interpretations. Annu. Rev. Mater. Res, 40, 271-292 (2010).

37. Li, N., Liu, L. \& Zhang, M. The role of friction to the indentation size effect in amorphous and crystallized Pd-based alloy. J. Mater. Sci, 44, 3072-3076 (2009).

38. Dey, A., Chakraborty, R. \& Mukhopadhyay, A. K. Enhancement in nanohardness of soda-lime-silica glass. J. Non-Cryst. Solids, 357, 2934-2940 (2011).

\section{Figures}
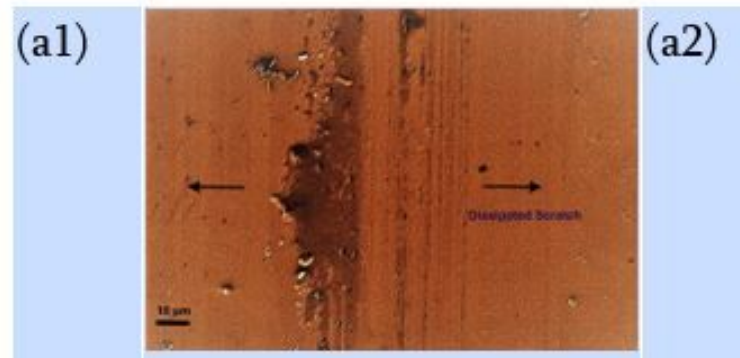

(b1)

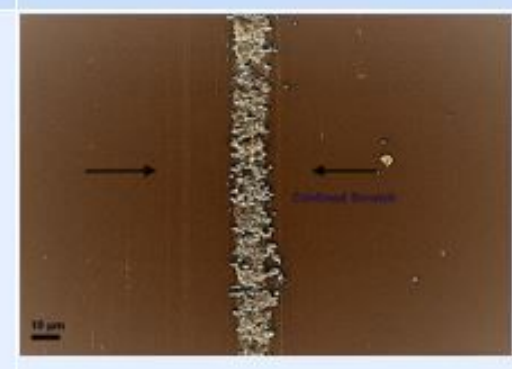

(b2)

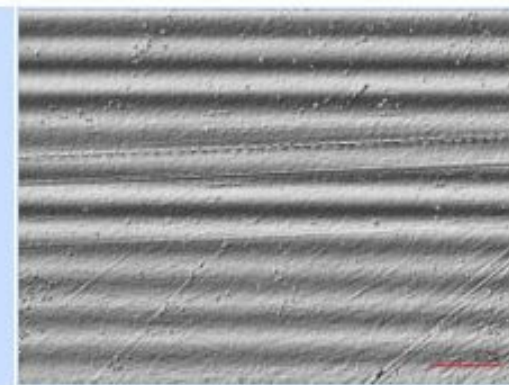

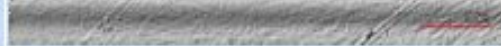

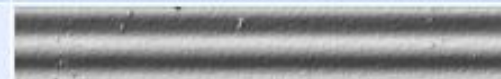

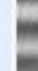

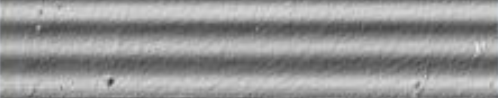

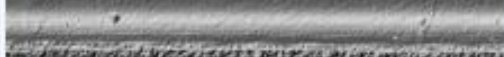

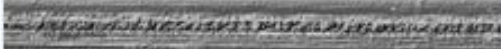

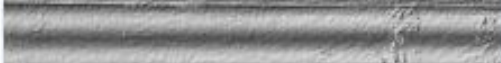

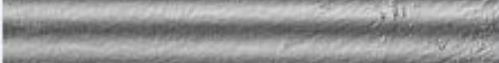

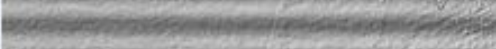

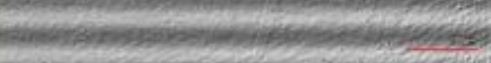

(a3)

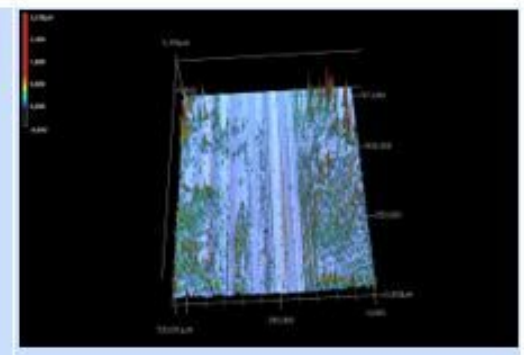

(b3)

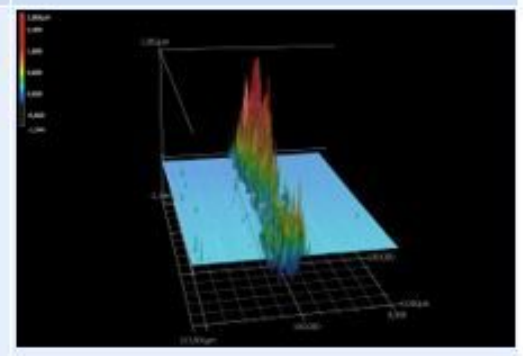

\section{Figure 1}

SEM, DIC and LSM (projected) images of scratch generated at $5 \mathrm{~N}$ on (a) untreated (b) heat-treated $\left(510^{\circ} \mathrm{C}, 30\right.$ minutes) SLS glass surface. 

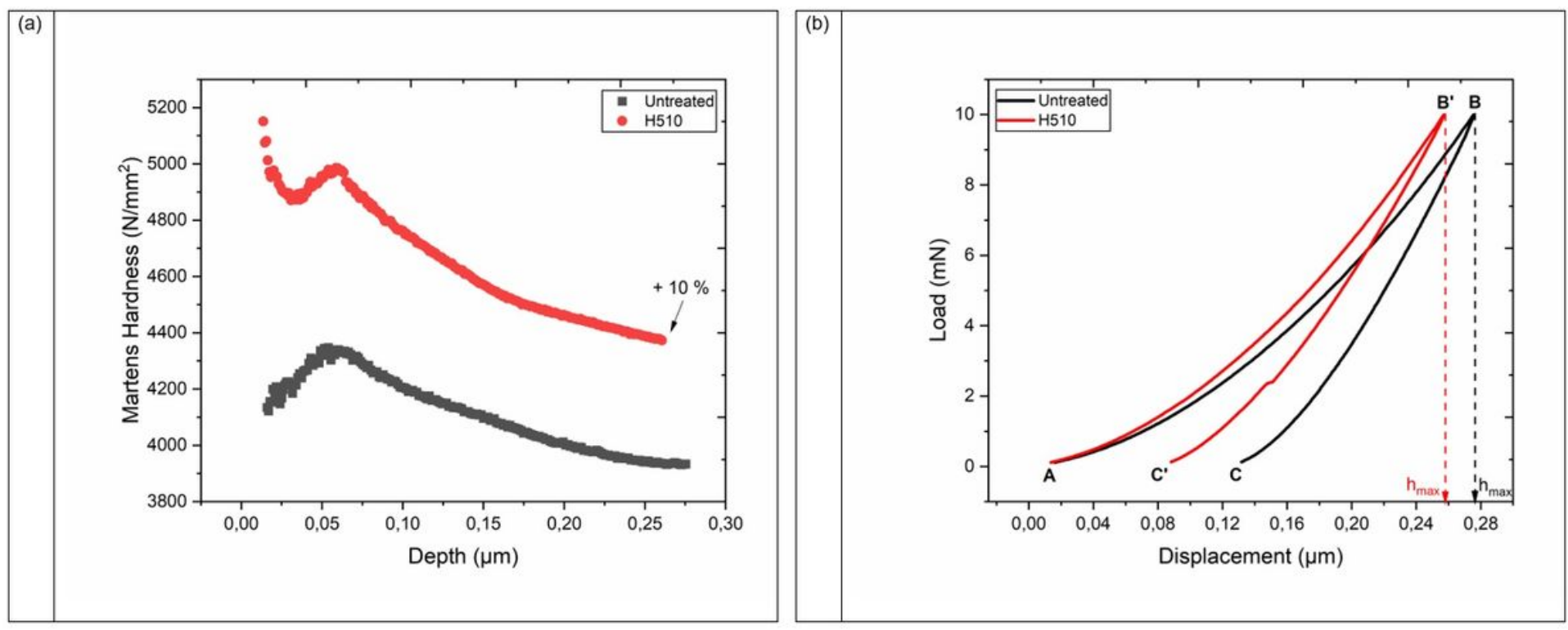

\section{Figure 2}

(a) Comparative illustration of variation of hardness as a function of depth from the un-treated and heattreated SLS glass surfaces. The indentation size effect (ISE) due to dis-location strengthening necessary to accommodate plastic deformation, in addition to fric-tion between the indenter and specimen surface [36,37], may not be neglected at shallow depths below $100 \mathrm{~nm}$. The Martens hardness in the ordinate (yaxis) contains an axis-break up to $3900 \mathrm{~N} / \mathrm{mm} 2$. (b) Corresponding load-displacement curves illustrating the loading cycle ( $A B$ : untreated and $\left.A B^{\prime}: H 510\right)$ and unloading cycle representative of elastic recovery (BC: untreated and $\left.B^{\prime} C^{\prime}: H 510\right)$. The serration observed in the unloading cycle ( $\left.B^{\prime} C^{\prime}\right)$ of $\mathrm{H} 510$ specimen is a reflection of local relaxation processes during elastic recov-ery, which is predominantly more active during the unloading process than during load-ing [38]. 


\section{(a)}

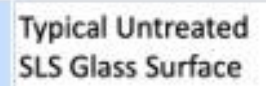

Typical Untreated
SLS Glass Surface

Surface

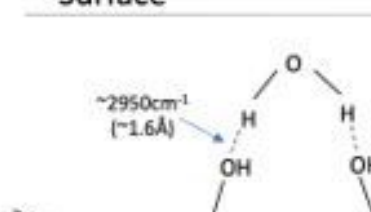

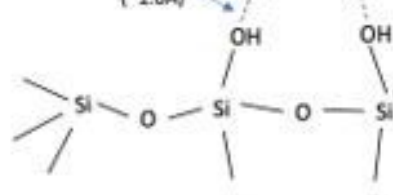

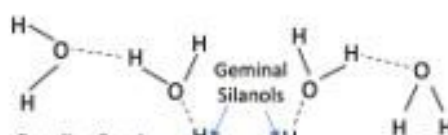

$\mathrm{O}_{\mathrm{H}} \mathrm{H}_{\mathrm{H}}^{\mathrm{O}} \mathrm{H}_{\mathrm{O}^{\prime}} \mathrm{H}_{\mathrm{H}}$

Outer

Film

\section{(1)}
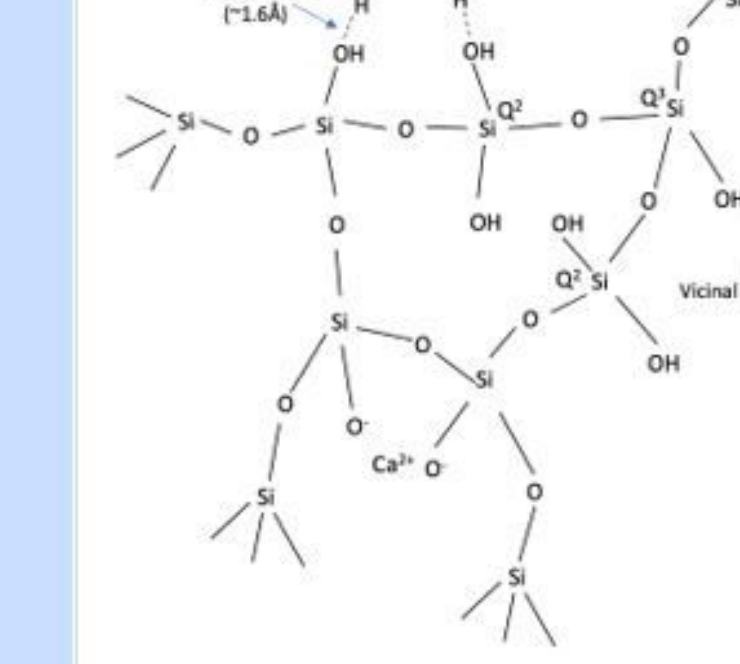

(b)

\section{SLS Glass Surface}

Heat-Treated at $510^{\circ} \mathrm{C}$

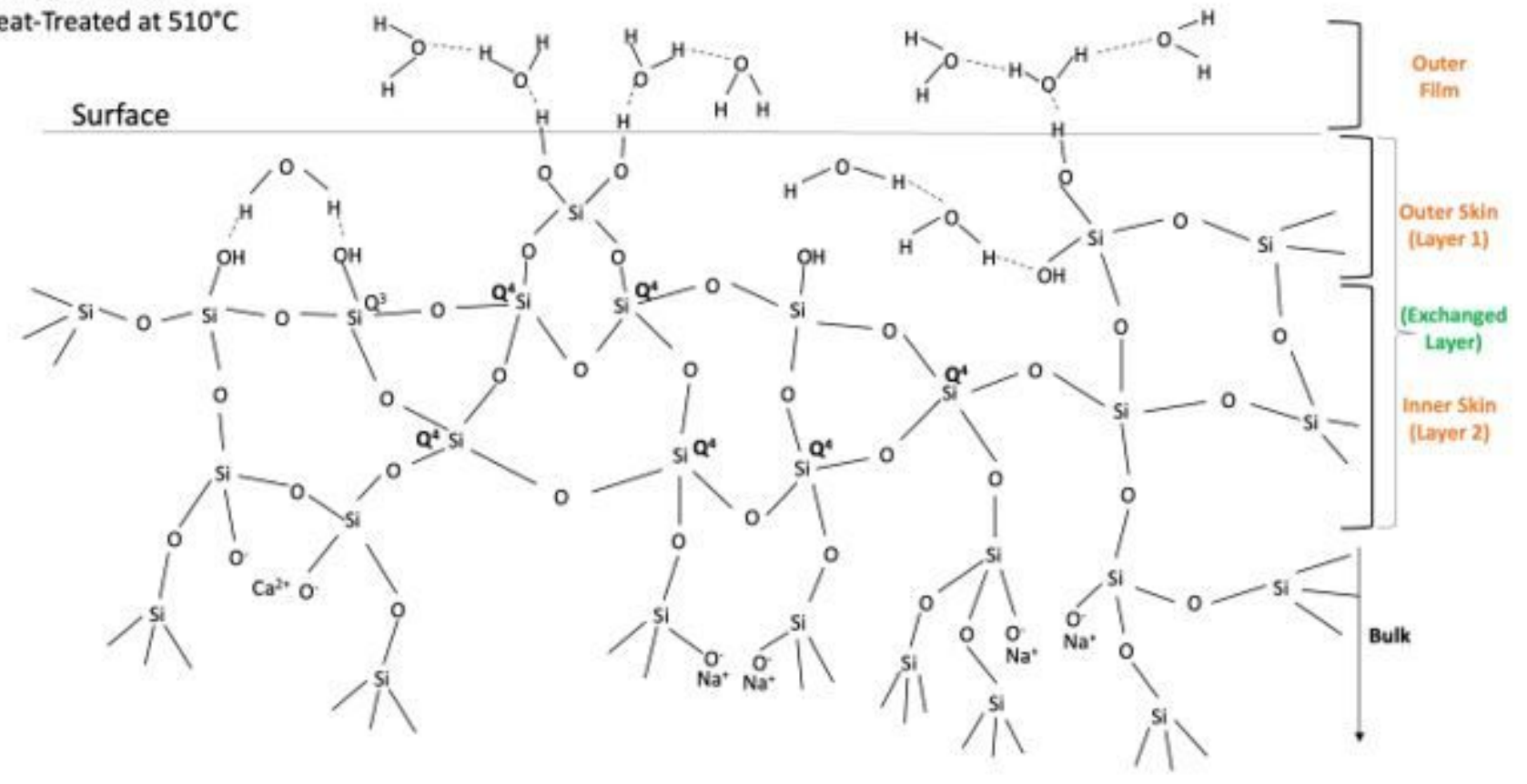

\section{Figure 3}

Typical surface structural schematics of SLS glass (a) untreated (b) heat-treated at $510^{\circ} \mathrm{C}$ for 30 minutes. The surface $\mathrm{OH}$ groups pertaining to physisorbed and chemisorbed water molecules in the outer skin (layer 1 ) were assigned by ATR-IR signals. The inner skin (layer 2) containing vicinal silanol groups are speculated to repolymerize into Q4 units during sub-Tg heat-treatment [26] to harden the glass surface. 
The depth of the SiO2-rich glass skin (exchanged layer) is in the order of few nanometers, which depends on ther-mal history and atmospheric storage history, among other surface-influential factors.

(a)

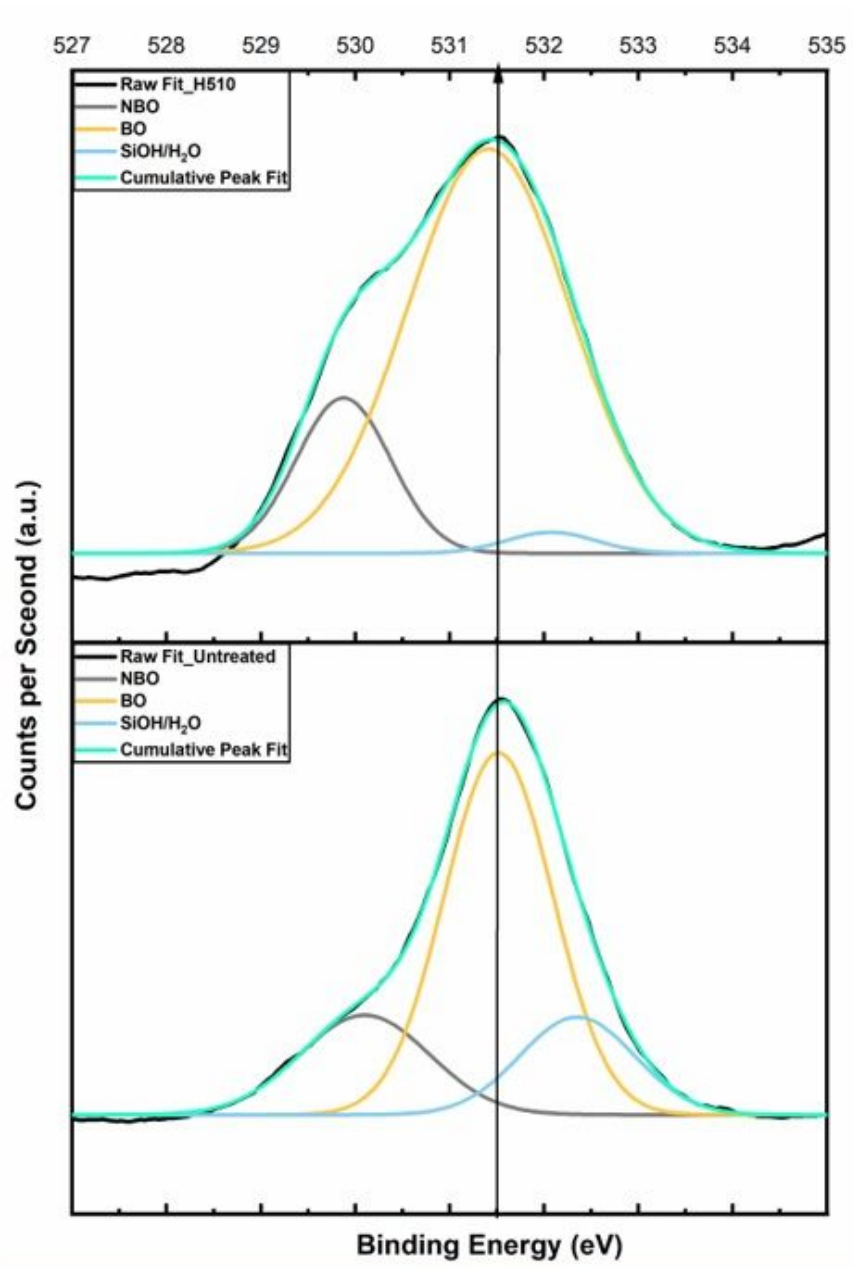

(b)

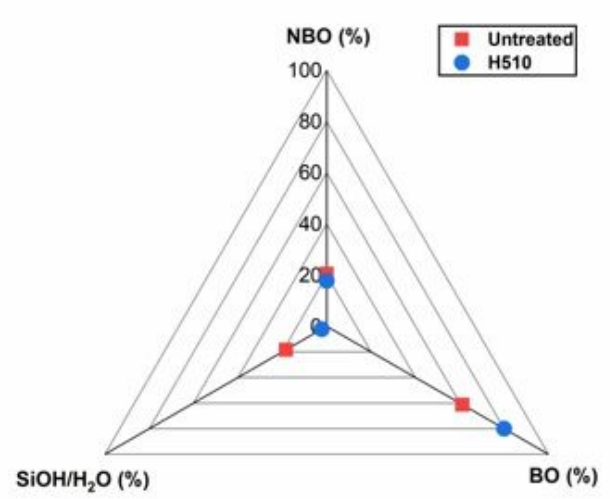

\section{Figure 4}

XPS results of untreated and heat-treated SLS surfaces $(0-5 \mathrm{~nm})($ a) $100 \%$ Gaussian de-convolution of 01s orbital (b) Comparative illustration of distribution of bridging oxygens (BOs), non-bridging oxygens (NBOs) and $\mathrm{SiOH} / \mathrm{H} 2 \mathrm{O}$ species on both the surfaces. 


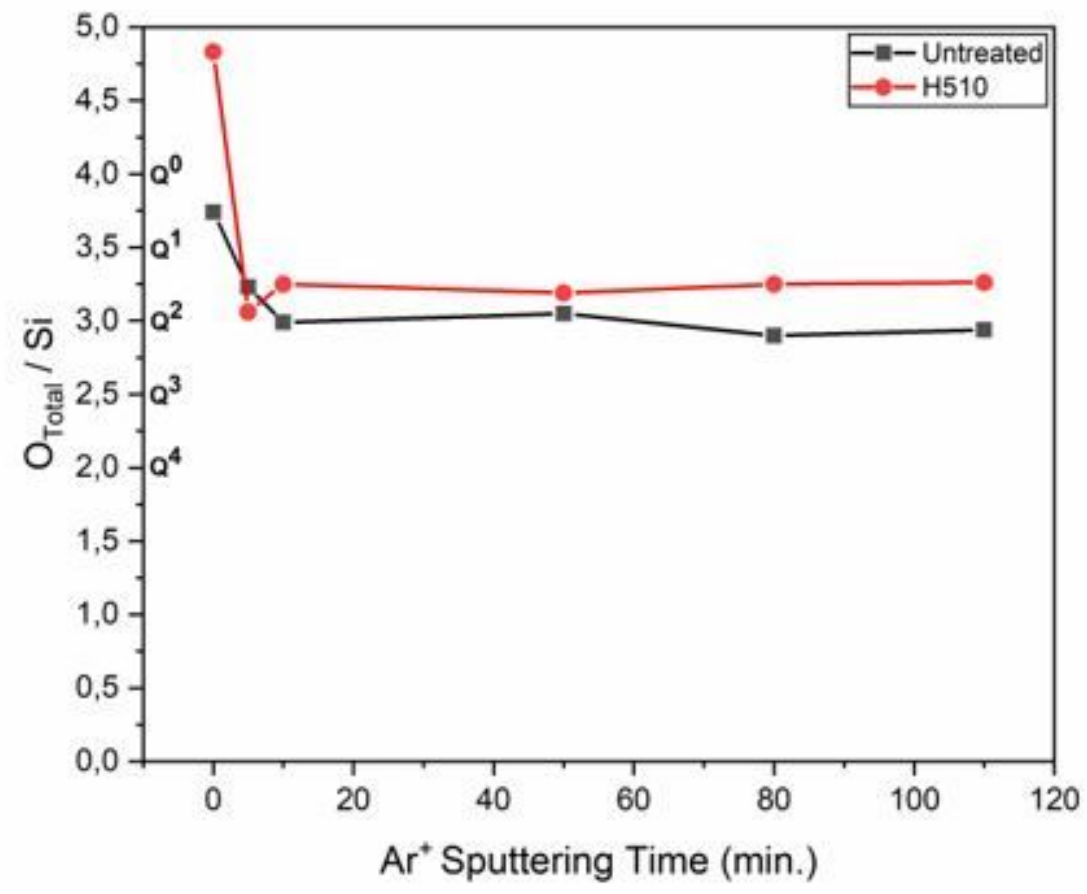

Figure 5

Comparative variation of total oxygen (OTotal) to silicon (Si) atomic ratio as a function of $\mathrm{Ar}+$ sputtering time (depth range $\sim$ 0-100 $\mathrm{nm}$ ) for untreated and heat-treated specimens. The relative sensitivity factor (RSF) was taken into consideration. Connecting lines act as guideline to the eye.

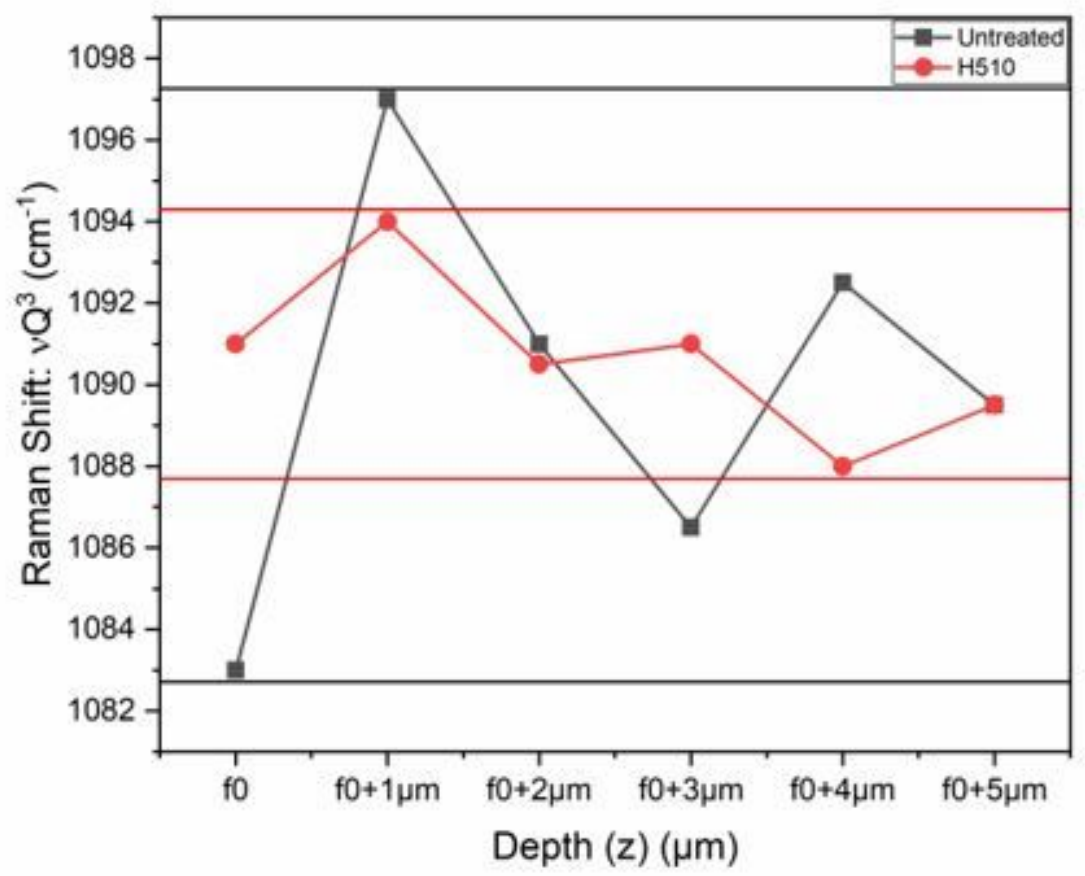


Figure 6

Comparative Raman shifts of the position of high frequency Q3 stretching band with depth up to $5 \mu \mathrm{m}$ pertaining to untreated and heat-treated specimens. Depth Resolution $\sim 1 \mu \mathrm{m}$.

(a)

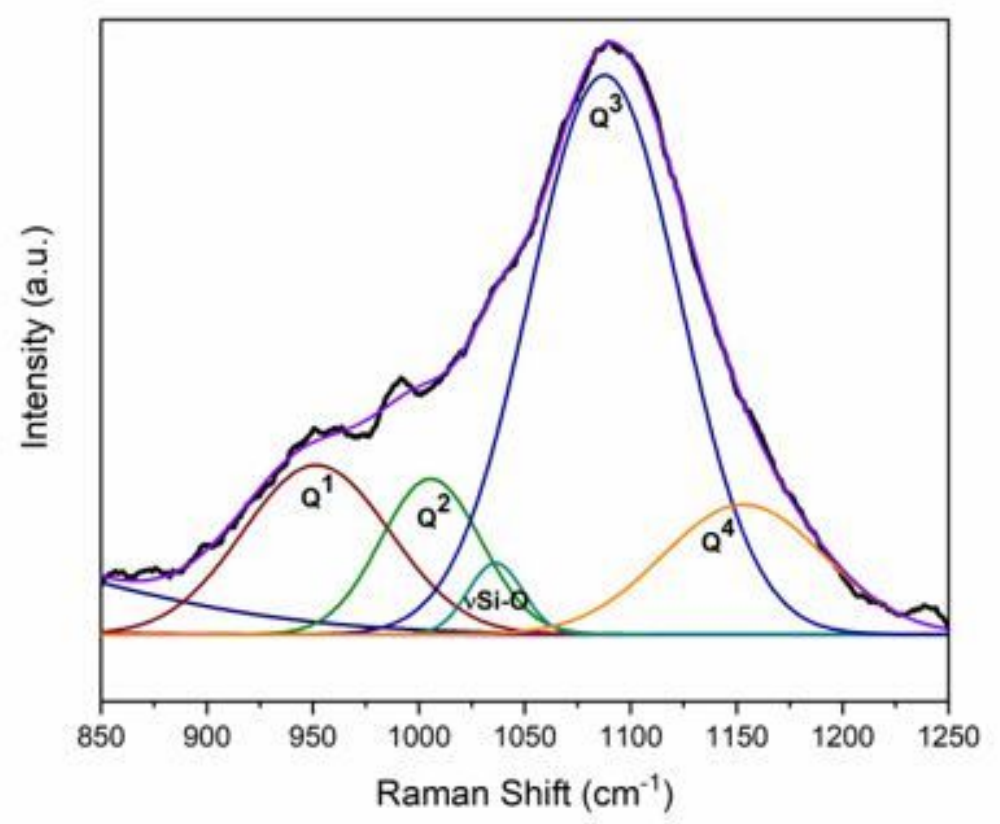

(b)

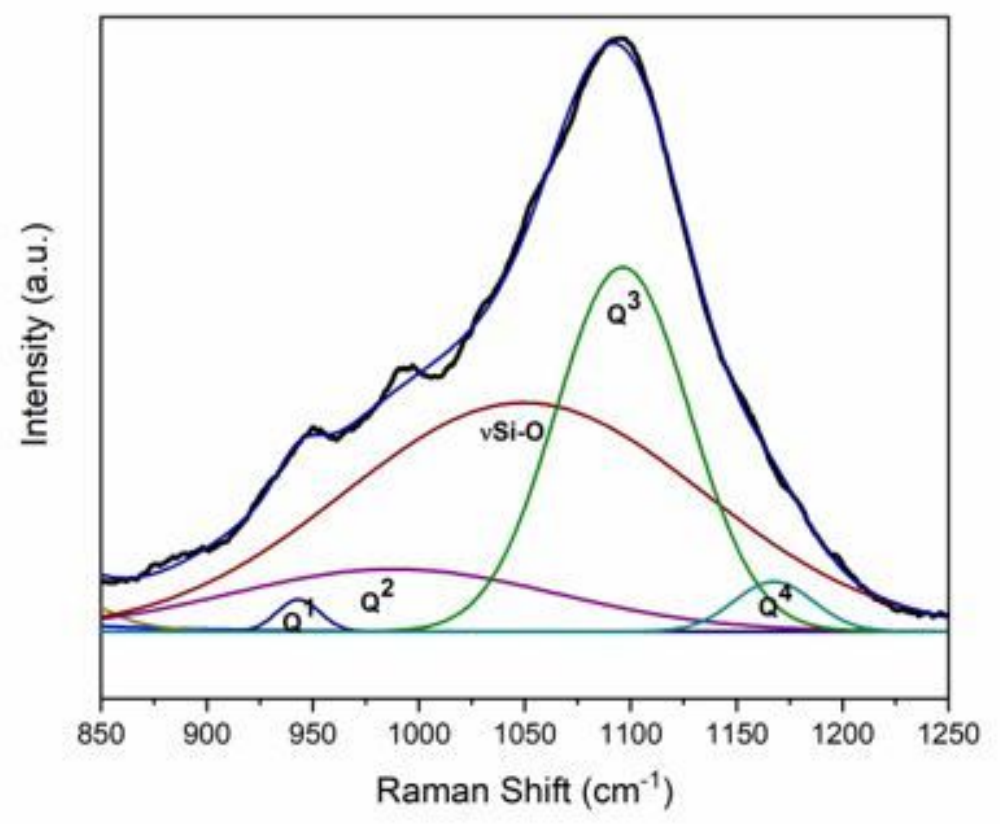

Figure 7

Gaussian deconvolution of HF Raman band $(850 \mathrm{~cm}-1$ to $1250 \mathrm{~cm}-1)$ indicating the over-lapping peaks corresponding to Qn species present in the scratched network of (a) un-treated and (b) heat-treated 
surfaces. (R-square > 0.99 in both spectral fits). 